\title{
MANFAAT EKONOMI EKOWISATA HIU PAUS (Rhincodon typus) DI KAMPUNG AKUDIOMI DISTRIK YAUR KABUPATEN NABIRE
}

\author{
Economic Benefit of Whale Shark Tourism in Akudiomi Village, District Yaur, \\ Nabire Regency \\ Muhammad Fajar Marsaoly ${ }^{1}$, Marjan Bato ${ }^{1}$, dan Nurhani Widiastuti ${ }^{1 *}$ \\ Jurusan Perikanan, FPIK UNIPA, Manokwari, 98314, Indonesia \\ *Korespondensi : n_widiast@yahoo.com
}

\begin{abstract}
ABSTRAK
Model pemanfaatan hiu paus yang memberi manfaat ekonomi sekaligus memberikan perlindungan terhadap hiu paus dapat dilakukan melalui pariwisata dengan konsep ekowisata. Kampung Akudiomi merupakan salah satu kampung di wilayah Taman Nasional Teluk Cenderawasih yang memiliki objek dan daya tarik wisata berbasis hiu paus. Meningkatnya kunjungan wisatawan ke wilayah ini telah memberi manfaat ekonomi bagi berbagai pihak. Tujuan penelitian ini yaitu mengetahui manfaat ekonomi yang diperoleh para pemangku kepentingan dan secara khusus mengetahui tingkat kesejahteraan pelaku usaha wisata lokal dari aktifitas ekowisata hiu paus. Studi dilakukan pada bulan Maret hingga Mei 2014 di Kampung Akudiomi Kabupaten Nabire Propinsi Papua. Hasil penelitian menginformasikan bahwa kegiatan ekowisata berbasis hiu paus di perairan Akudiomi telah memberikan dampak positif yaitu mendatangkan manfaat ekonomi bagi para pemangku kepentingan termasuk masyarakat lokal. Manfaat ekonomi yang diperoleh oleh masing-masing pihak berbeda-beda, tergantung dari kebijakan dalam penetapan tarif, serta jenis kegiatan dan jumlah kunjungan wisatawan. Meskipun telah memberi manfaat ekonomi, tingkat kesejahteraan pekerja wisata lokal masih tergolong rendah (33\%) dan sedang (67\%), secara umum kemampuan pendapatan perkapita lebih kecil dari tingkat konsumsi.
\end{abstract}

Kata kunci : Manfaat Ekonomi, Ekowisata, Hiu Paus, Kampung Akudiomi

\begin{abstract}
Model utilization of whale sharks that benefit the economy as well as providing protection against a whale shark can be done through tourism with the concept of ecotourism. Akudiomi village is one of the villages in the region of Teluk Cenderawasih National Park that has the object and attraction-based whale sharks. Increased tourist arrivals to the region has given economic benefits for all parties. The purpose of this research is to know the economic benefit gained by the stakeholders and in particular to know the welfare of the local travel business operators of whale shark ecotourism activities. The study was conducted from March to May 2014 in Kampung Akudiomi Nabire district of Papua province. The results of the study informs that activity-based ecotourism whale sharks in the waters Akudiomi had a positive impact that is bringing economic benefits to all stakeholders, including local communities. The economic benefits obtained by each party is different, depending on the policies in the tariff, as well as the type of activity and the number of tourist visits. Although it has provided economic benefits, the welfare of the local travel trade is still relatively low (33\%) and moderate (67\%), the general ability of a per capita income lower than the level of consumption.
\end{abstract}

Key words :The Economic Benefits, Ecotourism, Whale Sharks, Akudiomi Village 


\section{PENDAHULUAN}

Keanekaragaman organisme di perairan Papua sangat tinggi dan salah satu yang menjadi unggulan yaitu hiu paus (Rhincodon typus) yang terdapat di Kawasan Konservasi Taman Nasional Teluk Cenderawasih (TNTC). Hiu paus adalah hiu terbesar di lautan, dengan panjang mencapai $20 \mathrm{~m}$ dan memiliki berat tubuh hingga 20 ton (Norman, 2005 dalam Stacey, $d k k ., 2008)$. WWF (2002) mengemukakan bahwa hiu paus merupakan ikan terbesar di dunia, dan dapat tumbuh mencapai panjang tubuh 20 meter dan berat 34 ton. Hiu paus di dunia dapat ditemukan di perairan tropis yang bersuhu hangat, kecuali di mediterranean. Hiu paus memiliki kemampuan untuk bermigrasi yang sangat jauh dan diketahui berada perairan tropis yang bersuhu hangat (Campagno, 1984; Norman, 2005 dalam Stacey, dkk., 2008). Hiu ini disebut hiu paus karena ukuran tubuhnya yang sangat besar dan bentuk kepalanya tumpul mirip paus. Meskipun ikan ini namanya hiu paus tapi ikan ini tidak menakutkan karena makanan utamanya adalah plank-ton.

Hiu paus semakin langka dan termasuk hewan yang terancam punah. Akibat dampak antropogenik yang mencakup penangkapan, sehingga Convention of Internasional Trade in Endangered Spesies of Wild Fauna and Flora (CITES) and on The Convention on The Conservation of Migratory Spesies of Wild Animals (CMS) memasukkan hiu paus dalam daftar appendiks 1 dan 2 (IOTC, 2012). Berdasarkan hasil pemantauan hiu paus yang dilakukan oleh WWF Indonesia Program Teluk Cenderawasih pada tahun 2012 hingga Maret 2014, dari 2000 foto hiu paus telah teridentifikasi 96 ekor hiu paus (WWF Indonesia, 2014). Potensi keberadaan hiu paus perlu mendapat perlindungan agar kelestariannya tetap terjaga sehingga dapat dimanfaatkan pada sektor pariwisata secara berkesinam-bungan.

Hiu paus dapat menjadi objek dan daya tarik wisata tersendiri yang dapat mengundang para wisatawan. Oleh karena itu, kegiatan ekowisata berbasis hiu paus dapat berkontribusi dalam peningkatan ekonomi daerah terutama masyarakat lokal. (Western, 1995). Untuk mencapai tujuan ekowisata secara berkelanjutan maka diperlukan suatu pengelolaan yang dapat mendukung pengembangan kegiatan ekowisata, sehingga mendatang-kan manfaat sebesar-besarnya bagi masyarakat lokal. Sejak menjadi objek dan daya tarik wisata berbasis hiu paus, Kampung Akudiomi telah memberi manfaat ekonomi bagi berbagai pihak pemangku kepentingan. Namun hingga kini, informasi tentang manfaat ekonomi tersebut belum diketahui. Tujuan penelitian ini yaitu mengetahui manfaat ekonomi yang diperoleh para pemangku kepentingan dan secara khusus mengetahui tingkat kesejahteraan pelaku usaha wisata lokal dari aktifitas ekowisata hiu paus. Hasil penelitian ini diharapkan dapat menjadi sumber informasi dalam penyusunan kebijakan pengelolaan ekowisata hiu paus ke depan.

\section{METODE PENELITIAN}

Metode penelitian yang dilakukan bersifat deskriptif. Metode ini digunakan dengan tujuan mendeskripsikan secara sistematis dan akurat mengenai faktafakta, sifat-sifat serta hubungan antara fenomena yang sedang diselidiki seperti halnya pada tujuan penelitian ini. Untuk mendeskripsikan fenomena atau permasalahan dalam penelitian ini dibutuhkan data primer dan data sekunder. Data primer diperoleh dari wawancara dan data sekunder dari instansi terkait data yang dibutuhkan dalam penelitian.

\section{Waktu dan Tempat}

Studi lapang dilakukan selama 2 bulan, yaitu pada bulan Maret - Mei 2014 di Kawasan Konservasi Taman Nasional Teluk Cenderawasih (TNTC) Kampung Akudiomi Kabupaten Nabire Propinsi Papua. 


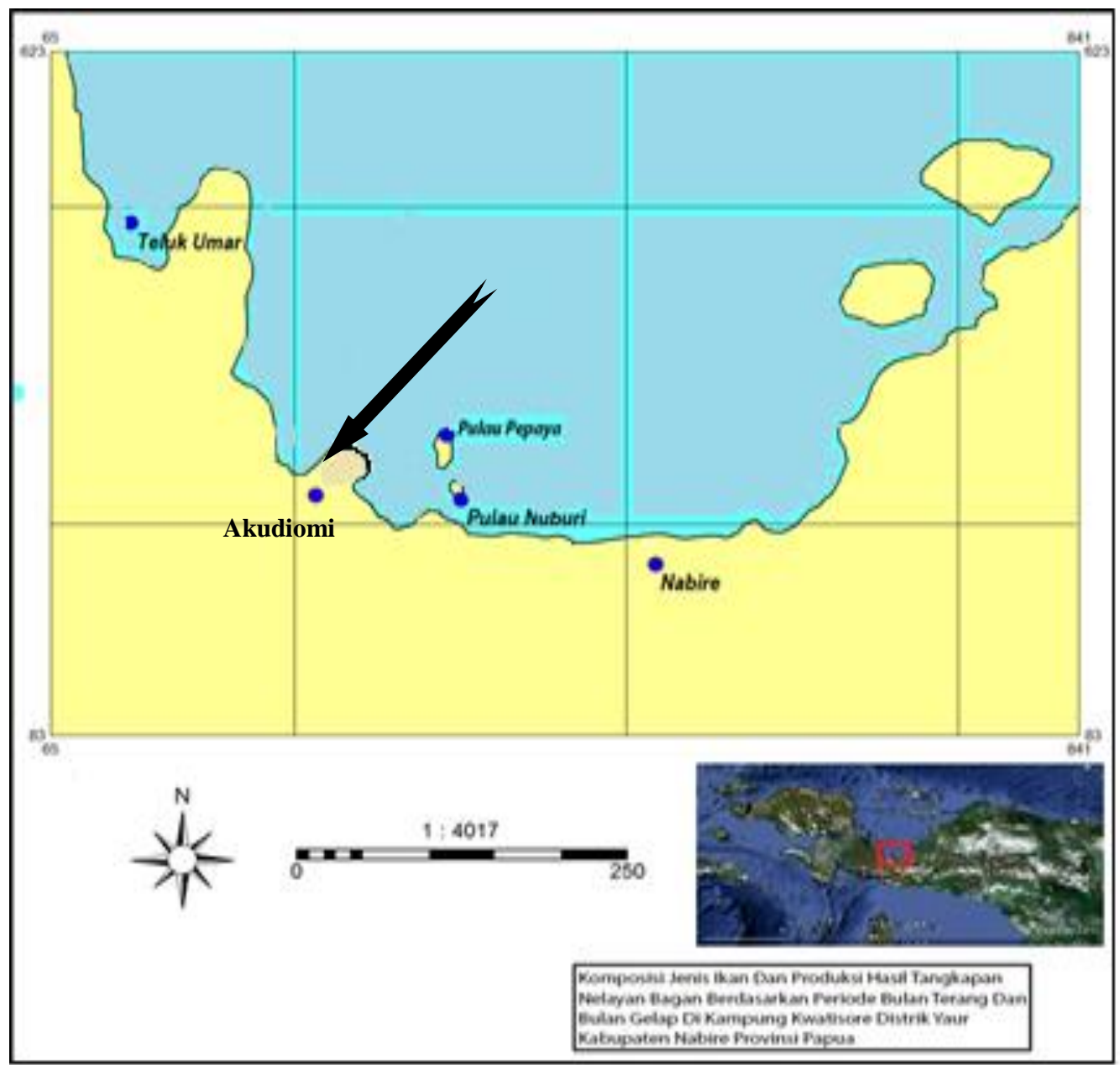

Gambar 1. Peta lokasi penelitian (Sumber: Arebo, 2014)

\section{Alat dan Bahan}

Alat dan bahan yang yang digunakan dalam penelitian ini, yaitu alat tulis menulis, kuisioner, kamera, GPS receiver, dan bahan kontak.

\section{Metode Pengambilan Data dan Pemi- lihan Rseponden}

Data primer dan data sekunder yang digunakan dalam penelitian ini merupakan dasar untuk menjelaskan fenomena yang diamati dalam penelitian. Responden ditentukan berdasarkan kelompok responden yang sesuai dengan jenis data yang dibutuhkan. Khusus bagi pelaku wisata lokal, sebanyak 26 responden diwawancarai untuk mengetahui tingkat kesejahteraan keluarga. Di samping itu, untuk melengkapi data maka dibutuhkan informan kunci dari tokoh-tokoh yang berpengaruh di kampung baik tokoh adat, agama dan pemerintahan.

\section{Metode Analisis Data}

Analisis data yang digunakan dalam penelitian yaitu analisis deskriptif dan skoring. Analisis deskriptif bertujuan untuk untuk mengetahui kondisi umum lokasi penelitian, sosial-ekonomi masyarakat lokal, dan potensi sumberdaya perairan/ pesisir. Adapun analisis Analisis skoring dilakukan untuk mengetahui manfaat ekonomi dari kegiatan ekowisata baik langsung maupun tidak langsung melalui perhitungan tingkat kesejahteraan masyarakat lokal berdasarkan karakteristik indikator kesejahteraan masyarakat seperti, tingkat pendapatan keluarga, tingkat konsumsi/pengeluaran keluarga, tingkat pendidikan keluarga, tingkat kese- 
hatan keluarga, kondisi perumahan serta fasilitas perumahan yang dimiliki (Agusniatih, 2002 dalam Bato, 2013) yang mana setiap variabel diskoring dan diberi bobot untuk mendapatkan nilai/ bobot yang nantinya dijadikan sebagai variabel untuk klasifikasi masyarakat. Adapun kategorinya yaitu :

a. Tingkat kesejahteraan tinggi dengan skor 51-63

b. Tingkat kesejahteraan sedang dengan skor 36-50

c. Tingkat kesejahteraan rendah dengan skor 21-35
Penentuan klasifikasi tersebut dilakukan dengan cara mengalikan bobot dengan skor, nilai tertinggi kemudian dikurangi dengan hasil kali bobot dengan skor terendah yang kemudian hasilnya dibagi tiga untuk membentuk tiga kategori dengan interval yang sama. Adapun indikator yang diadopsi dari Badan Pusat Statistik (BPS, 2011 dalam Bato, 2013) untuk menganalisis klasifikasi masyarakat guna mengetahui tingkat kesejahteraan masyarakat Kampung Akudiomi, Kabupaten Nabire tersaji pada tabel 1.

Tabel 1. Indikator Tingkat Kesejahteraan Masyarakat

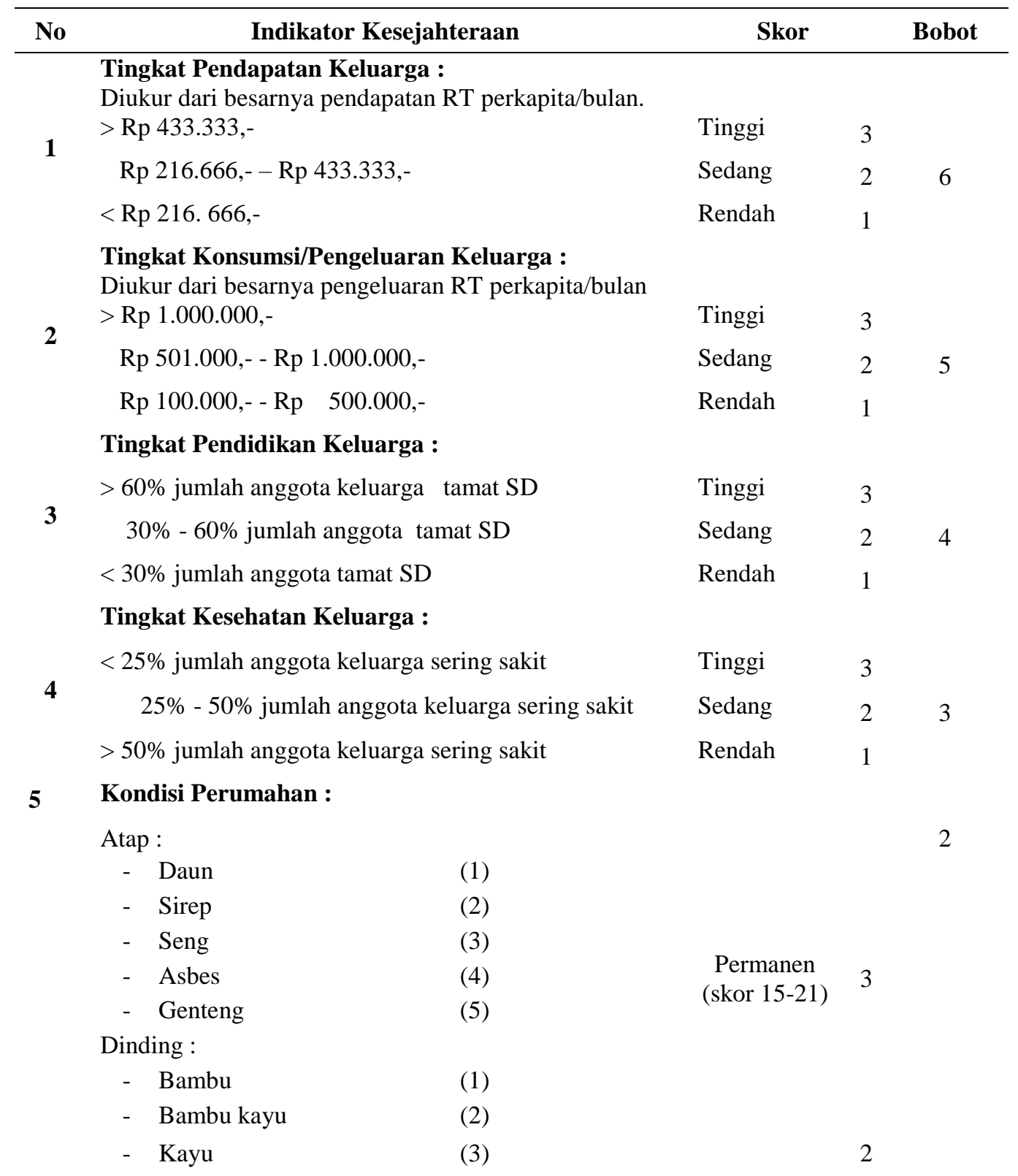


- Setengah tembok

- Tembok

Status kepemilikan :

- Numpang

- Sewa

- Milik sendiri

Jenis lantai :

- Tanah

- Papan

- Plester
(4)

(5)

(1) permanen

(2)

(3)

(1)

(2)

(3)

\begin{tabular}{ll}
\hline No & Indikator Kesejahteraan \\
\hline & - Ubin \\
& - Porselin
\end{tabular}

Luas lantai : Skor Bobot

Tidak permanen (skor 5-9)

$$
\begin{aligned}
& \text { - Sempit }\left(50 \mathrm{~m}^{2}\right) \\
& \text { - Sedang }\left(50-100 \mathrm{~m}^{2}\right) \\
& \text { - Luas }\left(>100 \mathrm{~m}^{2}\right)
\end{aligned}
$$

\section{Fasilitas Perumahan :}

Pekarangan :

- Sempit $\left(50 \mathrm{~m}^{2}\right)$

- Sedang (50-100 m²

- $\operatorname{Luas}\left(>100 \mathrm{~m}^{2}\right)$

Hiburan :

- Radio

- Tape recorder

(1)

- TV

- Video

Pendingin :

- Alam

- Kipas angin

- Lemari es

- AC

Sumber penerangan :

- Lampu tempel

- Petromak

- Listrik

Lengkap (skor 21-27) 3 1

Bahan bakar :

- Kayu

- Minyak tanah

- Gas

Sumber air :

$$
\begin{aligned}
& \text { - Sungai } \\
& \text { - Air hujan } \\
& \text { - Mata air } \\
& \text { - } \quad \text { Sumur gali } \\
& \text { - PAM }
\end{aligned}
$$

Tidak lengkap (skor 7-13)

MCK : 


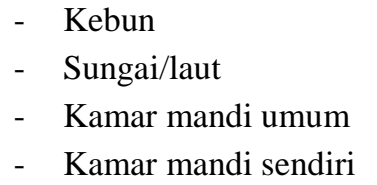

Sumber : Badan Pusat Statistik (2011) dalam Bato (2013)

\section{HASIL DAN PEMBAHASAN}

\section{Manfaat kegiatan ekowisata di Kam- pung Akudiomi}

Ekowisata merupakan usaha konservasi yang paling mudah dijual dan oleh karenanya dipertimbangkan dalam pengambilan keputusan mengenai tata guna lahan. Ekowisata juga dapat menciptakan lapangan pekerjaan di daerahdaerah yang terpencil (Lindberg, $d k k, 1995)$. Ekowisata dapat menciptakan kesempatan kerja bagi masyarakat setempat, dan mengurangi kemiskinan, dimana penghasilan ekowisata diperoleh dari jasa-jasa wisata untuk wisatawan seperti : fee pemandu, ongkos transportasi, homestay, menjual kerajinan tangan. Ekowisata membawa dampak positif terhadap pelestarian lingkungan dan budaya asli setempat (Direktorat Produk Pariwisata, $d k k$., 2009). Wibowo (2007) mengemukakan bahwa dengan adanya pengembangan ekowisata di kawasan wisata Merapi - Merbabu telah menarik kunjungan wisatawan dan membuka kesempatan kerja.

Ekowisata berbasis hiu paus bukan saja memberikan kenikmatan terhadap wisatawan, namun ekowisata ini dapat memberikan manfaat atau keuntungan ekonomi bagi pengelola, pemerintah maupun masyarakat lokal melalui penarikan biaya-biaya dalam kegiatan ekowisata seperti yang telah dilakukan di Donsol, Filipina. Di Filipina, telah menentukan biaya-biaya yang harus dikeluarkan oleh para wisatawan yang enggan menjumpai atau berinteraksi langsung dengan hiu paus. Salah satu biaya yang harus dikeluarkan oleh wisatawan yaitu membayar sewa perahu untuk menempuh perjalanan ke tempat hiu paus mencapai
US\$ 50 untuk tujuh orang wisatawan per perahu, US\$ 200 per orang untuk membayar pemandu penyelaman. Dengan adanya manfaat yang dapat dirasakan oleh masyarakat lokal dari ekowisata hiu paus tentunya mereka dengan sendirinya akan melakukan per-lindungan terhadap keberadaan dan kelangsungan hidup dari hiu paus tersebut (Quiros, 2005).

Potensi kemunculan hiu paus sepanjang tahun yang dimiliki oleh Akudiomi merupakan keunggulan yang dapat menarik lebih banyak pengunjung untuk datang mengunjungi Akudiomi. Berdasarkan informasi dari Manager Kali Lemon Dive Resort, objek yang selalu dikunjungi wisatawan yang datang ke Akudiomi adalah hiu paus, bahkan dilakukan berulang-ulang selama di penginapan. Untuk melakukan kegiatan, wisatawan harus mengeluarkan sejumlah uang untuk membayar tarif masuk kawasan, membeli souvenir, membeli puri di nelayan bagan. Oleh karena itu, adanya kegiatan ekowisata di Kampung Akudiomi dapat memberikan dampak positif yaitu manfaat secara ekonomi. Namun, tinggi rendahnya keuntungan pada waktu tertentu sangat relatif, karena tergantung tingginya musim atau minat kunjungan wisatawan pada waktu ter-tentu.

Kegiatan ekowisata di Kampung Akudiomi telah memberikan keuntungan oleh masyarakat kampung, pemerintah kampung, nelayan bagan, pengelola kawasan, operator wisata dan Pemerintah daerah (PEMDA) kabupaten Nabire. Berikut bagan alir manfaat atau keuntungan yang diperoleh oleh pemangku kepentingan (stakeholders) tersebut dari kegiatan ekowisata di Kampung Akudiomi.

Perolehan manfaat ekonomi oleh beberapa stakeholders tersebut berasal dari sumber pendapatan yang berbeda. 
Berikut gambaran mengenai cara dan sumber pendapatan dari masing-masing stakeholders.

\section{a. Manfaat Ekonomi bagi kampung}

Retribusi wisata bagi kampung bersumber dari hasil musyawarah adat
Kampung Akudiomi distrik Yaur tentang pengaturaan tarif masuk wisatawan yang dilaksanakan pada hari senin tanggal 19 September 2013, yang memutuskan bahwa tarif masuk kawasan Kampung Akudiomi sebagai berikut :

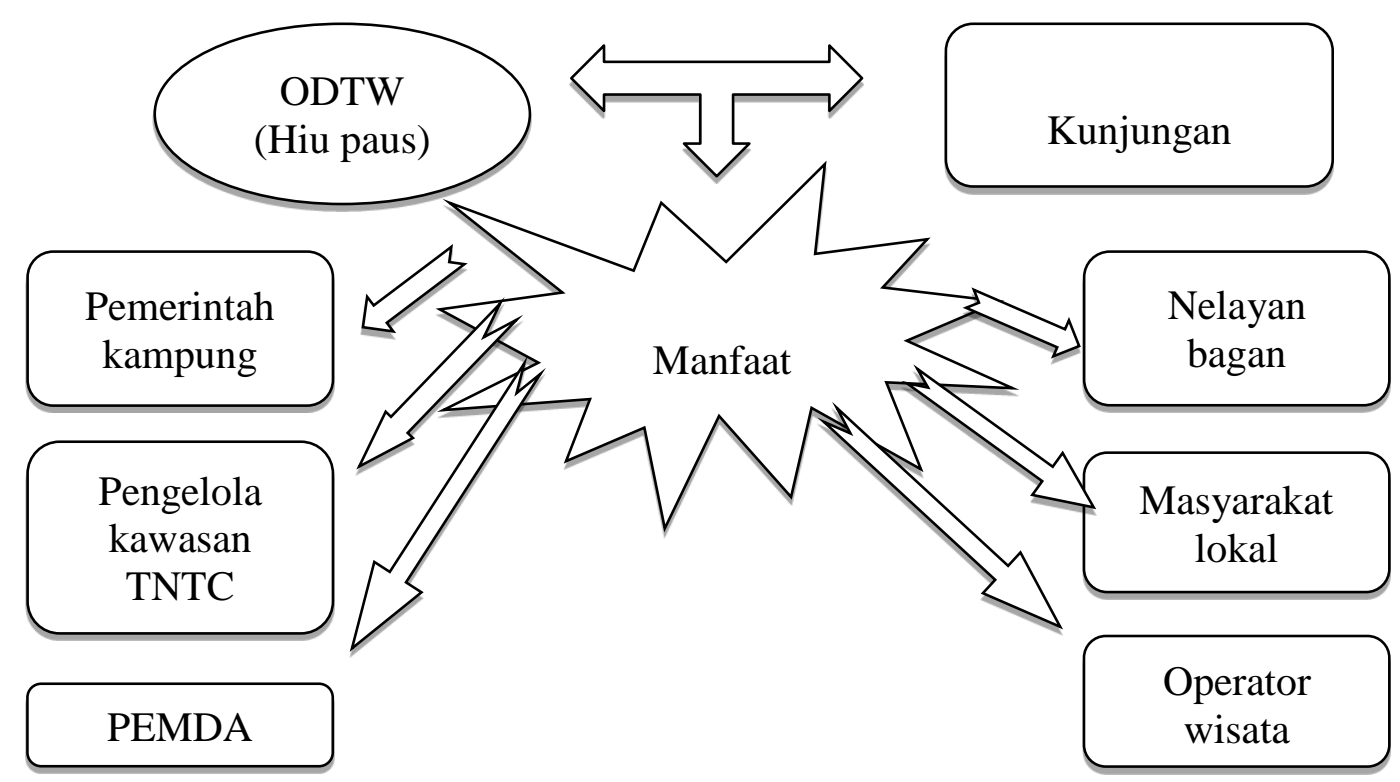

Gambar 2. Bagan Alir Manfaat Hiu Paus Bagi Stakeholders

1. Warga negara Indonesia (WNI) Rp 100.000/orang

2. Warga negara asing (WNA) Rp 300.000 /orang

Jadi, dengan adanya ketentuan ini maka setiap wisatawan harus membayar sesuai ketentuan tersebut. Pembayaran tarif berlaku untuk per trip. Misalnya rencana wisatawan berada di kawasan 3 malam pembayarannya tetap satu kali pembayaran saat pertama kali datang.

\section{b. Manfaat Ekonomi bagi pengelola kawasan TNTC}

Pengelola kawasan memperoleh pendapatan dari penetapan tarif/pungutan masuk kawasan dan besar kecilnyanya tarif tersebut tergantung dari jenis kegiatan yang dilakukan wisatawan. Berikut daftar tarif yang dikenakan kepada wisatawan yang akan melakukan kegiatan di Taman Nasional Teluk Cenderawasih (TNTC) berdasarkan Peraturan Pemerintah Nomor 59 tahun 1998 tentang tarif atas jenis Penerimaan Negara Bukan
Pajak (PNBP) yang berlaku pada Departemen Kehutanan dan Perkebunan.

Pembayaran pungutan ini dilakukan bersamaan dengan pembuatan surat izin masuk kawasan konservasi (SIMAKSI). Pembayaran ini dapat dilakukan oleh orang lain misalnya wisatawan yang berkunjung melalui jalur operator maka yang mengurus semua yang terkait kunjungannya adalah operator wisata.

\section{c. Manfaat Ekonomi bagi Pemerintah Daerah (Pemda)}

Suatu upaya pemanfaatan sumberdaya alam sekaligus untuk memperoleh pendapatan sebagai salah satu sumber Pendapatan Asli Daerah (PAD). Pemda melakukan kerjasama dengan masyarakat lokal. Kerja sama ini dengan cara Pemda memfasilitasi peralatan wisata kepada masyarakat untuk menjadi pengelola wisata. Hal ini dimaksudkan agar masyarakat memperoleh keuntungan dari sumberdaya alam yang ada pada masyarakat itu sendiri. Sistem pengelolaan pendapatan yang diperoleh dari kegiatan 
wisata yaitu dengan sistem bagi hasil yang telah disepakati bersama antara pemda dengan masyarakat dalam sebuah surat perjanjian. Sistem ini dengan menggunakan prosentase, 25\% untuk Pemda dan $75 \%$ untuk masyarakat (pengelola wisata).

\section{d. Manfaat Ekonomi bagi operator wisata}

Berdasarkan wawancara dengan manager resort pendapatan yang diperoleh oleh operator dapat bersumber dari biayabiaya yang harus dikeluarkan oleh wisatawan yang berencana menginap di resort. Banyak sedikitnya pendapatan per trip tergantung dari rencana awal wisatawan untuk berapa lama menginap/trip. Pembayaran kepada operator dilakukan dua tahap. Tahap pertama sebelum wisatawan berkunjung harus mengirimkan $50 \%$ dari total biaya per trip dan tahap kedua 50\% lagi diakhir kegiatan.

\section{e. Manfaat Ekonomi bagi Masyarakat lokal}

Pengembangan kegiatan ekowisata yang dilakukan di Kampung Akudiomi didasarkan pada manfaat yang dapat diperoleh kampung maupun masyarakatnya dengan memanfaatkan potensi kemunculan hiu paus yang dimiliki oleh masyarakat Kampung Akudiomi. Manfaat dari kegiatan ini dapat menjadi salah satu sumber pendapatan keluarga di samping pekerjaan pokoknya. Manfaat yang diperoleh masyarakat hanya jika ada kunjungan wisatawan ke kampung. Manfaat yang diperoleh berasal dari kreatifitas membuat kerajinan tangan yang dapat dijual kepada para wisatawan dan menjadi souvenir dari kunjungan tersebut.

Jenis souvenir yang dibuat oleh masyarakat berupa gantungan kunci yang bentuknya seperti hiu paus, ikan duyung (Dugong dugon), ikan lumba-lumba (Delphinidae), ikan nemo (Pomacentridae) serta dayung yang bermotif indah sesuai daerahnya. Bahan baku yang digunakan untuk membuat souvenir terbuat dari kayu. Souvenir ini dibuat bervariasi dalam segala ukuran dengan panjang yang berkisar dari $10 \mathrm{~cm}$ sampai 1 meter dengan harga yang bervariasi pula tergantung ukurannya. Harga souvenir yang disediakan berkisar Rp 20.000,00 sampai Rp 500.000,00.

Tabel 2. Pungutan Masuk Kawasan Taman Nasional Teluk Cenderawasih

\begin{tabular}{|c|c|c|c|c|}
\hline No & & $\begin{array}{l}\text { nis penerimaan negara bukan pajak } \\
\text { (PNBP) }\end{array}$ & Satuan & $\begin{array}{c}\text { Harga satuan } \\
(\mathbf{R p})\end{array}$ \\
\hline \multirow[t]{3}{*}{1} & \multicolumn{4}{|c|}{ Penerimaan dari pengusahaan pariwisata alam } \\
\hline & A & Pungutan ijin pengusahaan wisata alam & На & 1.080 .000 \\
\hline & B & Iuran hasil usaha pariwisata alam & $\begin{array}{l}\text { Keuntungan bersih T.A. } \\
\text { yang bersangkutan }\end{array}$ & $10 \%$ \\
\hline \multirow[t]{17}{*}{2} & \multicolumn{4}{|c|}{ Penerimaan dari pungutan masuk kawasan TNTC } \\
\hline & A & Pengunjung & & \\
\hline & & 1. Wisatawan mancanegara & Orang & 15.000 \\
\hline & & 2. Wisatawan nusantara & Orang & 1.500 \\
\hline & B. & Peneliti & & \\
\hline & & 1. Wisatawan mancanegara & & \\
\hline & & a. $1-15$ hari/ $1 / 2$ bulan & Orang & 75.000 \\
\hline & & b. 16-30 hari/ 1 bulan & Orang & 150.000 \\
\hline & & c. $1-6$ bulan/ $1 / 2$ tahun & Orang & 300.000 \\
\hline & & d. $1 / 2-1$ tahun & Orang & 450.000 \\
\hline & & e. Diatas 1 tahun & Orang & 600.000 \\
\hline & & 2. Wisatawan nusantara & & \\
\hline & & a. $1-15$ hari/ $1 / 2$ bulan & Orang & 25.000 \\
\hline & & b. $16-30$ hari/ 1 bulan & Orang & 50.000 \\
\hline & & c. $1-6$ bulan $/ 1 / 2$ tahun & Orang & 100.000 \\
\hline & & d. $1 / 2-1$ tahun & Orang & 150.000 \\
\hline & & e. Diatas 1 tahun & Orang & 200.0000 \\
\hline
\end{tabular}


C. Kendaraan darat

1. Roda 2 (dua)

2. Roda 4 (empat)

Unit

2000

Jenis penerimaan negara bukan pajak

\begin{tabular}{lclr}
\hline No & $\begin{array}{c}\text { Jenis penerimaan negara bukan pajak } \\
\text { (PNBP) }\end{array}$ & Satuan & $\begin{array}{c}\text { Harga satuan } \\
(\text { Rp })\end{array}$ \\
\hline D & Kendaraan air & & \\
& 1. Kapal motor sampai dengan 40 PK & Unit & 25.000 \\
2. Kapal motor sampai 41-80 PK & Unit & 50.000 \\
& 3. Kapal motor diatas 80 PK & Unit & 75.000
\end{tabular}

E. Pengambilan/snapshot

1. Wisatawan mancanegara
a. Film komersial
b. Video komersial
c. Handycam
d. Foto

Sekali masuk

2.500 .000

Dokumen cerita

2.000 .000

Non komersial

125.000

Non komersial

30.000

2. Wisatawan nusantara
a. Film komersial
b. Video komersial
c. Handycam
d. Foto

Sekali masuk

1.500 .000

Dokumen cerita

1.000 .000

Non komersial

12.500

Non komersial

3.000

F. Olahraga/rekreasi alam bebas

1. Wisatawan mancanegara
a. Menyelam (diving)
1 jam
50.000
b. Snorkling
1 jam
40.000
c. Berkemah
1 jam
20.000
d. Kano
1 jam
25.000
e. Selancar
1 jam
40.000

2. Wisatawan nusantara

\begin{tabular}{lll} 
a. Menyelam (diving) & 1 jam & 40.000 \\
b. Snorkling & 1 jam & 30.000 \\
c. Berkemah & 1 jam & 15.000 \\
d. Kano & 1 jam & 20.000 \\
e. Selancar & 1 jam & 30.000 \\
\hline
\end{tabular}

Sumber : Bidang pengelolaan TNTC Nabire (1998)

Selain kerajinan tangan, sebagian masyarakat memperoleh manfaat dari kegiatan wisata yaitu melalui penjualan dagangan kios. Para pendamping wisatawan seperti pengelola kapal pesiar membeli barang dagangan masyarakat seperti kue, makanan ringan, rokok, sayur untuk bahan makanan di kapal mereka. Selain itu juga, manfaat perjalanan wisata yang diperoleh oleh masyarakat lokal yaitu memperoleh uang secara langsung karena adanya kunjungan ke objek wisata yang berada di hak ulayat keluarga. Salah satu contoh yaitu pengamatan burung cende-rawasih yang berada di hak ulayat ke-luarga tersebut.

Penyelenggaraan kegiatan ekowisata tentunya memberikan manfaat bagi masyarakat setempat, namun kadangkala manfaat itu belum bisa dirasakan oleh semua masyarakat setempat. Hasil analisis menunjukkan $46 \%$ dari total 26 responden telah memperoleh manfaat, sedangkan sisanya $54 \%$ belum memperoleh manfaatnya. Berikut diagram yang menyajikan persentase kelompok masyarakat yang sudah dan belum memperoleh manfaat dari kegiatan wisata. Adapun karakteristik pekerjaan yang berkaitan dengan manfaat ekowisata oleh masyarakat Kampung Akudiomi sebagaimana tampak pada Tabel 3.

Berdasarkan tabel 3, tampak bahwa masing-masing kelompok masyarakat memperoleh manfaat wisata dari sumber perolehan yang berbeda-beda. Manfaat tertinggi yaitu manfaat berupa perasaan senang dengan adanya kegiatan wisata di 
kampung dengan tingkat persentase $100 \%$ yang artinya seluruh responden mendapatkan manfaat berupa perasaan senang. Sedangkan persentase terendah yaitu berupa penjualan barang dagangan kios dan pengetahuan mengenai kelestarian lingkungan dengan masing-masing memiliki poin $4 \%$ yang artinya hanya $4 \%$ dari total responden yang memperoleh manfaat berupa pendapatan dari hasil penjualan barang dagangan kios.

Tabel 3. Karakteristik Pekerjaan yang Berkaitan dengan Manfaat Kegiatan Ekowisata di Kampung Akudiomi oleh Masyarakat Lokal

\begin{tabular}{|c|c|c|c|}
\hline Kode & Jenis manfaat & $\begin{array}{c}\text { Jumlah } \\
\text { responden }\end{array}$ & Persentase $(\%)$ \\
\hline $\mathbf{A}$ & Dapat menjual kerajinan tangan & 4 & 15 \\
\hline $\mathbf{B}$ & Dapat menjual barang dagangan kios & 1 & 4 \\
\hline $\mathbf{C}$ & Merasa senang & 26 & 100 \\
\hline D & Mengetahui pentingnya kelestarian alam & 1 & 4 \\
\hline $\mathbf{E}$ & $\begin{array}{l}\text { Menjadi anggota kelompok menanam yang dibentuk } \\
\text { resort }\end{array}$ & 2 & 8 \\
\hline $\mathbf{F}$ & $\begin{array}{l}\text { Mendapat bantuan biaya sekolah anak dari } \\
\text { pendapatan kampung yang bersumber dari sektor } \\
\text { pariwisata }\end{array}$ & 2 & 8 \\
\hline
\end{tabular}

Sumber : Data primer, 2014

\section{f. Retribusi bagi nelayan bagan}

Pendapatan yang diperoleh bersumber dari adanya kunjungan wisatawan ke bagan untuk berinteraksi dengan Hiu paus. Kegiatan interaksi ini agar dapat berjalan baik serta wisatawan dapat merasa puas dengan kemunculan hiu paus dalam waktu yang relatif lama maka dibutuhkan ikan puri untuk memberi makan hiu paus tersebut. Oleh karena itu, jika wisatawan ingin berinteraksi dengan hiu paus dapat membeli ikan puri tersebut dari nelayan bagan. Harga ikan puri per coolbox $\mathrm{Rp} 300.000,-$ tapi terkadang untuk interaksi satu hari penuh, mulai dari jam 07.00 WIT - 16.00 WIT wisatawan dapat membayarnya sebesar Rp 1.000.000. Dengan demikian, dengan adanya wisatawan ke bagan dapat menjadi sumber pendapatan sampingan bagi nelayan bagan.

Beberapa stakeholders yang memperoleh keuntungan dari kegiatan ekowisata di Kampung Akudiomi tersebut, hal ini menunjukkan bahwa adanya kegiatan ekowisata telah memberikan dampak positif yaitu mendatangkan keuntungan ekomoni bagi stakeholders termasuk masyarakat Kampung Akudiomi. Keuntungan yang besar dan kecil tergantung dari jumlah pengunjung dan jenis kegiatan yang dilakukan. Keun- tungan yang diperoleh oleh masingmasing stakeholders berbeda-beda. Perbedaan keuntungan ini tergantung dari kebijakan dalam penetapan tarif yang ditetapkan oleh masing - masing stakeholders. Khusus keuntungan yang diperoleh oleh masing-masing orang di Kampung Akudiomi tergantung dari keinginan untuk berpartisipasi, kekreatifan membuat kerajinan tangan (souvenir) yang dapat dijual kepada wisatawan. Tafalas (2010) mengemukakan bahwa manfaat kegiatan ekowisata di Meos Mansaar Raja Ampat bagi masyarakat melalui beberapa jenis aktifitas yang dilakukan, diantaranya yaitu sebagai karyawan operator wisata, pemilik jasa penginapan (homestay), jasa transportasi, pemilik areal untuk atraksi wisata (pengamatan burung cendera-wasih) dan atraksi memberi makan ikan laut.

Berdasarkan beberapa jenis kegiatan tersebut, terdapat beberapa jenis kegiatan yang belum dilakukan sebagai sarana untuk memperoleh manfaat ekowisata di Kampung Akudiomi, yaitu sebagai pemilik jasa penginapan dan jasa transportasi. Berdasarkan hal tersebut, perlu adanya pengembangan dan penggunaan sarana milik masyarakat yang dapat mendukung kegiatan ekowisata dan keuntungan bagi masyarakat Kampung Akudiomi. 


\section{Tingkat Kesejahteraan Masyarakat Lokal Pekerja Wisata}

Manfaat ekonomi yang diperoleh oleh pekerja wisata dideskripsikan berdasarkan perhitungan tingkat kesejahteraan keluarga dengan menggunakan panduan berupa data indikator kesejahteraan. Data yang diperoleh dan dianalisis dengan metode scoring menunjukkan bahwa tingkat kesejahteraan karyawan pekerja wisata sebesar $33 \%$ terklasifikasi dalam tingkat kesejahteraan rendah (skor 21-35) dan 67\% tingkat kesejahteraannya tergolong sedang (skor 36-50) sedangkan untuk tingkat kesejahteraan yang tergolong tinggi tidak ada. Dari analisis skoring terhadap variabel dalam indikator tingkat kesejahteraan terlihat bahwa nilai/skor dari variabel pendapatan memberikan jumlah skor yang tinggi dalam pengakumulasian skor dari tiap-tiap variabel untuk penentuan kategori keluarga pada tingkat kesejahteraannya. Berdasarkan kuantifikasi pada variabel pendapatan ( $\mathrm{S} \times \mathrm{B}$ ) dari masingmasing responden menunjukkan selisih skor yang sangat signifikan antara keluarga pekerja yang tergolong dalam tingkat kesejahteraan rendah dengan yang tergolong sedang dibandingkan dengan variabel tingkat kesejahteraan lainnya. Hal inilah yang sangat mempengaruhi tinggi dan rendahnya total skoring dari kuantifikasi semua jenis variabel (S x B) yang hasilnya digunakan untuk mengklasifikasikan masing-masing keluarga ke dalam kategori tingkat kesejahteraan tinggi, sedang atau rendah.

Tinggi rendahnya pendapatan perkapita dipengaruhi oleh besar kecilnya pendapatan keluarga dan banyak sedikitnya jumlah keluarga sehingga akan berdampak pada kemampuan perkapita untuk konsumsi atau penggunaan pendapatan untuk memenuhi kebutuhan. Salah satu faktor yang mempengaruhi tingginya pengeluaran sehari-hari adalah harga barang di lokasi tersebut. Kondisi dunia perekonomian seperti tingginya jumlah pengeluaran telah terjadi di lokasi penelitian ini dimana harga barang dua kali lipat harga pembelian di pusat kota.
Kemampuan konsumsi disini memiliki arti bahwa apakah pendapatannya bisa mencukupi ataukah tidak untuk memenuhi kebutuhannya sehingga dapat dikategorikan ke dalam kelompok kondisi keuangan yang seimbang atau tidak. Kondisi tersebut mendeskripsikan bahwa tingkat pendapatan tidak sama besar dengan tingkat konsumsi. Jika pendapatan lebih besar dari konsumsi/ pengeluaran maka termasuk kategori kondisi yang seimbang (balance) dan jika pendapatan lebih kecil dari tingkat konsumsi maka kondisi keuangannya termasuk ke dalam kategori tidak seimbang (no balance).

Analisis data menunjukan bahwa kondisi keuangan pekerja tidak seimbang (no balance) karena kemampuan pendapatan perkapita lebih kecil dari tingkat konsumsi atau pendapatannya tidak cukup untuk memenuhi kebutuhannya. Ketidakmampuan pendapatan untuk memenuhi tingkat konsumsi dilihat berdasarkan selisih pendapatan dengan pengeluaran. Dari hasil analisis diperoleh selisih rata-rata dari semua pekerja wisata yaitu Rp 405.278,-. Angka ini menunjukan bahwa pendapatan yang masih dibutuhkan untuk memenuhi kebutuhan untuk mencapai titik keseimbangan keuangan (balance).

\section{KESIMPULAN}

Adanya kegiatan ekowisata berbasis hiu paus di perairan Akudiomi telah memberikan dampak positif yaitu mendatangkan keuntungan ekonomi bagi stakeholders termasuk masyarakat lokal. Besar kecilnya manfaat ekonomi dipengaruhi jumlah pengunjung dan jenis kegiatan yang dilakukan. Keuntungan yang diperoleh oleh masing-masing stakeholders berbeda-beda, tergantung dari kebijakan dalam penetapan tarif yang ditetapkan oleh masing - masing stakeholders. Kesejahteraan masyarakat pekerja wisata berbeda-beda. Hasil analisis menunjukkan bahwa tingkat kesejahteraannya masih tergolong rendah dan sedang. Terdapat Keluarga yang tingkat kesejahteraannya rendah sebesar $33 \%$ 
sedangkan yang tergolong tingkat kesejahteraan sedang terdapat $67 \%$ keluarga. Secara umum kemampuan pendapatan perkapita lebih kecil dari tingkat konsumsi.

\section{DAFTAR PUSTAKA}

Arebo B.D. 2014. Komposisi Dan Distribusi Jenis Lamun Di Kampung Akudiomi Distrik Yaur Kabupaten Nabire Provinsi Papua. Skripsi. Program Studi Manajemen Sumbedaya Perairan, Fakultas Peternakan Perikanan dan Ilmu Kelautan, Universitas Negeri Papua. Manokwari.

Bato, M.. 2013. Kajian Manfaat Kawasan Konservasi Perairan Bagi Pengembangan Ekowisata Bahari (Studi Kasus di Kawasan Konservasi Perairan Nusa Penida, Bali. Tesis. Sekolah Pascasarjana. Institut Pertanian Bogor. Bogor.

Bidang Pengelolaan TNTC Nabire. 1998. Pungutan Masuk Kawasan Taman Nasional Teluk Cenderawasih.

Compagno, Leonard J. V. 2002. Sharks Of The World: An Annotated and Illustrated Catalogue Of Shark Species Known to Date: Bullhead, Mackerel and Carpet Sharks. http://id.wikipedia.org/wiki/Hiu_p aus. Akses : 02-09-2013.

Direktorat Produk Pariwisata., Direktorat Jenderal Pengembangan Destinasi Pariwisata., Departemen Kebudayaan dan Pariwisata dan WWFIndonesia. 2009. Prinsip dan Kriteria Ekowisata Berbasis Masyarakat.

Heyman. D. William., R.T. Graham., B. Kjerive., R.E. Johannes. (2001). Whale Sharks Rhincodon typus Aggregate to Feed on Fish Spawn in Belize. Department of Geological Sciences and Marine Science Program, University of South Carolina. Columbia. South Carolina 29208. USA.

Iwanggin, O., M. 2014. Komposisi Jenis Ikan dan Produksi Hasil Tangkapan Nelayan Bagan Berda- sarkan Periode Bulan Terang Dan Bulan Gelap Di Kampung Akudiomi Distrik Yaur Kabupaten Nabire Provinsi Papua. Skripsi. Universitas Negeri Papua. Manokwari

Kurnianto, I., R. 2008. Pengembangan Ekowisata (Ecotourism) Di Kawasan Waduk Cacaban Kabu-paten Tegal. Tesis. Universitas Diponegoro Semarang. Semarang.

Lindberg, K., dan Hawkins,D.E. 1995. Ekowisata: Petunjuk Untuk Perencanaan Dan Pengelolaan. Yayasan Alami Mitra Indonesia. Jakarta.

Pramudji. 2002. Pengelolaan Kawasan Pesisir Dalam Upaya Pengembangan Wisata Bahari. Jurnal. Oseana, Volume XXVII 1, 2002 : 27-35.

Quiros, A. 2005. Whale Shark "Ecotourism" in the Philippines and Belize: Evaluating Conser-vation and Community Benefits. Journal. Volume 24.

Routledge. 1999. Marine Tourism (development, impacts and management). Mark Orams.

Stacey, N., Johana, K., Dwyer., Conrad, S., Mark, M. 2008. Assessing Traditional Ecological Knowledge of Whale Sharks (Rhincodon typus) in eastern Indonesia: A pilot study with fishing communities in Nusa Tenggara Timur. Research. Charles Darwin University. Australia.

Stacey, E., N., Johana., K., Mark, G., Meekan., Samuel, P., Jotham, N. 2012. Prospects for Whale Shark Conservation in Eastern Indonesia Through Bajo Tradisional Ecological Knowledge and CommunityBased Monitoring. Conservation and Society 10 (1) : 63-75, 2012

Tafalas, M. 2010. Dampak Pengembangan Ekowisata Terhadap Kehidupan Sosial Ekonomi Masyarakat Lokal (studi kasus ekowisata bahari pulau Mansuar Kabupaten Raja Ampat). Tesis. Sekolah Pasca Sarjana IPB. Bogor 
Western David. 1995. Ekoturism : Petunjuk Untuk Perencanaan dan Pengelola. The Ecotourism Society. Hal 3-10.

Wibowo. 2007. Dampak Pengembangan Ekowisata Kawasan Wisata Gunung Merapi-Merbabu Terha-dap Perubahan Struktur Masyarakat. Skripsi. Universitas Sebelas Maret. Surakarta.

WWF Indonesia. 2014. Pemantauan hiu paus di TNTC dan peluang pengembangan pemantauan di Indonesia. 
